\title{
Spatial cognition, body representation and affective processes: the role of vestibular information beyond ocular reflexes and control of posture
}

\author{
Fred W. Mast ${ }^{1,2}$, Nora Preuss ${ }^{1,2}$, Matthias Hartmann ${ }^{1,2}$ and Luzia Grabherr ${ }^{3}$ \\ ${ }^{1}$ Department of Psychology, University of Bern, Bern, Switzerland \\ ${ }^{2}$ Center for Cognition, Learning and Memory, University of Bern, Bern, Switzerland \\ ${ }^{3}$ Sansom Institute for Health Research, University of South Australia, Adelaide, SA, Australia
}

Edited by:

Stephane Besnard, INSERM U1075,

France

Reviewed by:

Caroline Gurvich, Monash

University, Australia

Kathrine Jauregui-Renaud, Instituto

Mexicano del Seguro Social, Mexico

Lionel Bringoux, Aix-Marseille

Université-Institut des Sciences

du Mouvement E.J. Marey UMR

CNRS 7287, France

*Correspondence:

Fred W. Mast, Department of

Psychology, University of Bern,

Fabrikstrasse 8, 3012 Bern,

Switzerland

e-mail: fred.mast@psy.unibe.ch
A growing number of studies in humans demonstrate the involvement of vestibular information in tasks that are seemingly remote from well-known functions such as space constancy or postural control. In this review article we point out three emerging streams of research highlighting the importance of vestibular input: (1) Spatial Cognition: Modulation of vestibular signals can induce specific changes in spatial cognitive tasks like mental imagery and the processing of numbers. This has been shown in studies manipulating body orientation (changing the input from the otoliths), body rotation (changing the input from the semicircular canals), in clinical findings with vestibular patients, and in studies carried out in microgravity. There is also an effect in the reverse direction; top-down processes can affect perception of vestibular stimuli. (2) Body Representation: Numerous studies demonstrate that vestibular stimulation changes the representation of body parts, and sensitivity to tactile input or pain. Thus, the vestibular system plays an integral role in multisensory coordination of body representation. (3) Affective Processes and Disorders: Studies in psychiatric patients and patients with a vestibular disorder report a high comorbidity of vestibular dysfunctions and psychiatric symptoms. Recent studies investigated the beneficial effect of vestibular stimulation on psychiatric disorders, and how vestibular input can change mood and affect. These three emerging streams of research in vestibular science are-at least in part-associated with different neuronal core mechanisms. Spatial transformations draw on parietal areas, body representation is associated with somatosensory areas, and affective processes involve insular and cingulate cortices, all of which receive vestibular input. Even though a wide range of different vestibular cortical projection areas has been ascertained, their functionality still is scarcely understood.

Keywords: vestibular system, vestibular imagery, multisensory integration, mental rotation, body representation, body schema, affect, mood

\section{INTRODUCTION}

The wide majority of vestibular research concerns basic oculomotor mechanisms and postural control. Over several decades a substantial body of research has been ascertained, including the perception of self-motion and neuronal circuits that underlie the vestibulo-ocular reflex (VOR). The nature of the VOR has inspired computational models with precisely defined input parameters, and single-cell recordings have provided first insights into the brain areas that are involved in the processing of vestibular input (Grüsser et al., 1990). With the advent of neuroimaging, researchers started to use ways to induce vestibular sensations while brain activation was assessed. This is a challenging procedure because most current neuroimaging techniques require a stable head position, and it is therefore not possible to investigate the neuronal correlates of vestibular stimuli as they occur during natural head movements. However, the use of caloric vestibular stimulation (CVS), galvanic vestibular stimulation (GVS), and high-frequency auditory stimuli (clicks or tone bursts) allow for inducing vestibular stimulation while the head remains stationary. This research provided important findings about the human cortical areas associated with the processing of vestibular stimulation. The exact locations and functions of vestibular cortical areas are still a matter of debate (Lopez and Blanke, 2011). A recent meta-analysis by Lopez et al. (2012b) could identify the core regions of the human vestibular cortex. These areas involve the Sylvian fissure, insula, retroinsular cortex, fronto-parietal operculum, and cingulate cortex. Despite some discrepancies between different studies about the cortical areas involved in vestibular stimulation (Lopez et al., 2012b; zu Eulenburg et al., 2012) there is absolutely 
no doubt about the existence of widespread cortical vestibular representations.

Interestingly, there is still a lack of knowledge about the functions these cortical vestibular networks are involved in and with what other networks they overlap. For example, it has been shown that neurons in the gaze-related frontal eye fields are modulated by rotation and translation (Ebata et al., 2004). In middle superior temporal area (MSTd), neurons respond to inertial motion in darkness. These neurons represent visual-vestibular integration for heading perception ( $\mathrm{Gu}$ et al., 2007). Neurons in the ventral intraparietal area (VIP) respond to passive translations (Schlack et al., 2002) and rotations (Bremmer et al., 2002). These areas in addition to the parieto-insular vestibular cortex (PIVC) demonstrate the cortical involvement in the processing of self-motion perception, heading and gaze control.

Most vestibular research focuses on the encoding of gravitoinertial signals and this is evident given the profound knowledge about the vestibular end organ, and its projections to brain stem and cerebellar areas. However, we think it will add to a more complete understanding of vestibular functions when including higher processing areas in future research. The use of neuroimaging will certainly contribute but it is noteworthy to point out these techniques are in essence correlational and do not permit drawing causal conclusions about the functions that are associated with a particular pattern of brain activation. In our view, the advancement of the field depends largely on the future use of innovative behavioral techniques, the use of which is absolutely necessary to tap into the mechanisms that underlie vestibular cortical processes.

PubMed and Web of Science were the main databases that we used in order to search the literature. The key word "vestibular" was used in combination with the search terms "cognition", "mental rotation" "spatial", "body representation", "somatosensory", "tactile", "body schema" and "pain" to retrieve the relevant articles. The identified literature was then hand-searched, and we excluded articles focusing exclusively on physiological mechanisms, remotely related neurological disorders (e.g., Morbus Parkinson), animal research, and, for the most part, memory research. The latter has been addressed in several review papers already, and therefore became a field of research that receives considerable attention already (Smith et al., 2010; Smith and Zheng, 2013). The main focus of this review article lies on studies using a manipulation of the vestibular input (e.g., body motion, CVS, GVS). Furthermore, the references of the included articles were screened and new studies that cite the identified articles were taken into consideration. The remaining articles can be clustered in three research areas: spatial cognition, body representation, and affective processes and disorders. We will outline below the relevant state of research in each of these areas separately. In each section, we discuss in brief the most relevant issues tied to the respective research area, followed by a broader discussion of higher vestibular processing at the end of this article.

\section{SPATIAL COGNITION}

The vestibular system has been identified as one of the most important sources of our sense of spatial orientation (see handbook chapter by Merfeld, 2012). The contribution of vestibular signals for various space-related cognitive functions becomes evident in patients suffering from vestibular loss. These patients show impairments in path integration, navigation and spatial memory (e.g., Brandt et al., 2005; Péruch et al., 2005; Guidetti et al., 2008). For example, patients with bilateral vestibular loss showed impaired performance in a virtual version of the Morris water maze (Schautzer et al., 2003; Brandt et al., 2005). Interestingly, these patients also showed decreased hippocampal volume (Brandt et al., 2005). In patients with unilateral vestibular loss, spatial memory deficits are subtle and they are not accompanied by a hippocampal atrophy (Hüfner et al., 2007, 2009). A substantial amount of research on the vestibular involvement in spatial memory has been gained from studies with vestibularlesioned rodents. This research strongly supports the notion that vestibular input is required for navigation and spatial memory (e.g., Baek et al., 2010; Besnard et al., 2012; Zheng et al., 2012). While no effects on hippocampal volume were found (Zheng et al., 2012), vestibular lesions can disrupt hippocampal theta rhythm (Russell et al., 2006), eliminate directional sensitivity in hippocampal head direction cells (Stackman et al., 2002), and lead to neurochemical and neurophysiological changes (Zheng et al., 2001, 2013). See Smith et al. (2010) for a complete review on the implications of vestibular information in memory in humans and animals alike. In this context it is noteworthy that in healthy human subjects, vestibular stimulation was found to enhance spatial and non-spatial memory (Bächtold et al., 2001; Wilkinson et al., 2008).

Interestingly, the vestibular system is not only involved in the processing of motion in the physical world, it also seems to play an important role in building and maintaining a mental representation of the world. Even though we are bound to physical space, we are able to represent objects and movements mentally in order to optimally predict actions, react to events, and solve problems. A case in point is mental rotation. Shepard and Metzler (1971) have shown that people rotate a mental representation of an object in order to match it with another similar object. The response times increase with increasing angular disparity between two objects, and thus embody the characteristics of real rotations. It has been shown that the mechanisms that underlie mental rotation processes are not exclusively visual in nature but they also involve motor processes (e.g., Wraga et al., 2005, for a review see Kosslyn et al., 2001). Not only can we rotate in our mind visual representations of objects but also a representation of our own body or body parts. This is the case when one imagines what one would see from a different viewpoint. Viewer rotations operate on the representation of one's own body and they can be performed independently of the actual state of the physical body. Vestibular areas process body information caused by real body movements (translations and rotations), and, given the large amount of cortical vestibular representations, it is conceivable that some of the areas are drawn upon in an off-line mode. This would imply that brain areas dedicated to the processing of real body motion are also in the service of mental imagery when wholebody motion is merely imagined but not executed. Interestingly, there is so far only one neuroimaging study testing vestibular imagery (zu Eulenburg et al., 2013a). They found activation in 
the inferior parietal lobules, and these activations were stronger in the left hemisphere. A left sided parietal activation is in line with several studies on imagined self-rotations (e.g., Just et al., 2001; Vingerhoets et al., 2001) even though the activation pattern reported by zu Eulenburg et al. (2013a) was more inferior in the parietal lobe. Zu Eulenburg et al. first exposed participants to yaw rotation in an upright position, and the participants later had to recall this sensation while lying supine in the scanner. Participants were not debriefed about the strategy they applied when they recalled previous vestibular sensations. Had the participants in the supine position reproduced in egocentric coordinates the yaw stimulation they experienced on the chair, it would have resulted in an imagined barbecue rotation, which implies a change in body position with respect to gravity. Changes in body position with respect to gravity can influence performance in mental imagery tasks (Mast et al., 2003). Clearly, behavioral techniques need to be refined in order to better assess what participants are doing when they recall from memory previously experienced vestibular sensations. As pointed out by zu Eulenburg et al. (2013a), they used a non-visual first-person strategy that differed from similar mental body transformation tasks, which require visual stimuli. Interestingly, no activation in many other areas belonging to the vestibular network (e.g., the human analog of the PIVC) has been revealed. Another neuroimaging study investigated imagined locomotion and the results show an overlap with real locomotion (la Fougère et al., 2010). However, imagined locomotion was associated with early visual activation and this suggests that participants used a visual rather than vestibular strategy. It is likely that participants imagined self-motion by means of visual flow, and, indeed, there was a deactivation of vestibular areas such as the inferior parietal lobule during imagery. Vestibular deactivation has been reported repeatedly during visually induced self-motion (e.g., Brandt et al., 2002). This discrepancy illustrates that subtle changes in how people perform mental imagery tasks can substantially change brain activation, and it will be a challenge for future research to narrow down the cognitive processes. For example, it needs to be controlled whether participants imagine as vividly as possible the experience of self-motion with or without the aid of imagined visual stimuli. A similar distinction is known for the assessment of motor imagery, for which a kinesthetic ${ }^{1}$ subscale and a visual subscale have been defined in the Vividness of Motor Imagery Questionnaire (VMIQ; Isaac et al., 1986). Inevitably, locomotion in real life stimulates the vestibular system, and if imagined locomotion reenacts the characteristics of real body motion we would expect involvement of vestibular areas so that kinesthetic imagery has more vivid perceptual qualities. However, it is possible that vestibular imagery may be inherently different from other types of sensory imagery such as visual or auditory. Therefore, it may be difficult for participants to perform vestibular imagery without relying on other sensory input (e.g., tactile or visual), which often accompanies the actual physical motion. However, vestibular stimulation can provoke a conscious

\footnotetext{
${ }^{1}$ The VMIQ-2 is a revised version of the original VMIQ (Roberts et al., 2008). It makes a more precise distinction between internal imagery (participants visually imagine performing an action) and kinesthetic imagery (participants imagine themselves performing an action).
}

experience of its own, and we are able to perceive self-motion despite the absence of concurrent extra-vestibular stimulation.

\section{VESTIBULAR INFLUENCES ON SPATIAL COGNITION}

An example of how vestibular input can interact with spatial processing can be found in the well established subjective visual vertical task (SVV). A luminous line is set to the apparently vertical orientation, and it has been shown that the SVV depends on the body orientation of the observer (e.g., Tarnutzer et al., 2010). Interestingly, variation of task demands changes the contribution of the gravity-receptive signals (Bronstein, 1999). Clinical studies with vestibular patients suggest less impairment in the perception of body position (Bisdorff et al., 1996; Bringoux et al., 2002) or the adjustment of the gravity-referenced eye level (Bringoux et al., 2007) when compared to the typical pattern known from the assessment of the SVV. Spatial orientation tasks are an interesting front door for further exploring spatial cognition because performance in cognitive tasks also changes as a function of body position. For example, changing the inputs of the otoliths by means of the orientation of the observer has an impact on how objects are mentally manipulated (Corballis et al., 1976, 1978; Gaunet and Berthoz, 2000; Mast et al., 2003). In the same vein, specific changes in mental transformation tasks have been investigated through own-body rotation (van Elk and Blanke, 2013), changing the input from the semicircular canals by CVS (Mast et al., 2006; Falconer and Mast, 2012), changing the input of the vestibular nerve by GVS (Lenggenhager et al., 2008; Dilda et al., 2012), microgravity studies (Matsakis et al., 1993; Leone et al., 1995; Grabherr et al., 2007; Dalecki et al., 2013) and clinical studies with vestibular patients (Grabherr et al., 2011; Péruch et al., 2011; Candidi et al., 2013). It is important to point out that some studies provide evidence that vestibular input influences performance in mental rotation tasks only then when the task involves a representation of one's own body or perspective (Lenggenhager et al., 2008; Dilda et al., 2012; Falconer and Mast, 2012). Congruent motion can facilitate mental rotation of one's own body (Falconer and Mast, 2012; van Elk and Blanke, 2013) while absent or disturbed vestibular input can impair it (Grabherr et al., 2007; Lenggenhager et al., 2008). Some studies on vestibular patients show deficits in mental transformation of bodies and objects alike, suggesting that spatial-cognitive abilities are more globally impaired in these patients (Péruch et al., 2011; Candidi et al., 2013), whereas there is also evidence for a more pronounced impairment in mental rotation of bodies (Grabherr et al., 2011). These studies demonstrate that vestibular input or the lack thereof can interfere with or facilitate specific cognitive tasks. Even though the sum of these studies do not yet provide a fully coherent picture as to how vestibular processes are nested within spatial transformation abilities, they provide first evidence that the processing of vestibular information overlaps with specific cognitive spatial abilities. It will be interesting to investigate how the effects of body position on cognitive tasks relate to the spatial orientation tasks mentioned above, and whether the underlying gravity-receptive mechanisms differ between tasks.

The vestibular-cognitive interactions described above focused on cognitive processes that included mental spatial transformation of an object, body or body part. Beside this, vestibular 
input can also influence the processing of information that is represented in a specific spatial order. An illustrative example are numbers. In Western cultures, small numbers are cognitively represented in the left, and large numbers in the right side of space, following the concept of the "mental number line" (see Hubbard et al., 2005, for a review). The small-left and largeright-association also depends on vestibular information. For example, tuning the head to the left side leads to the production of smaller numbers than turning the head to the right side in a random number generation task (Loetscher et al., 2008). Similar effects have been found with horizontal passive wholebody motion in the dark, thus separating the vestibular input from neck afferences (Hartmann et al., 2012b; see also Hartmann et al., 2012a). A related concept of the mental number line is the mental time line, assuming that also temporal events are represented with a spatial entity. According to the concept of the mental time line, past events are associated with left or back space, and future events with right or front space (e.g., Arzy et al., 2009; Ulrich and Maienborn, 2010; Ulrich et al., 2012). In accordance with this, Miles et al. (2010) found that thinking about the past is accompanied by backward body sway, and thinking about the future by forward body sway. Similarly, it has been shown that future-related words were processed faster during forward when compared to backward passive whole-body motion, pointing again to vestibular contributions to these effects (Hartmann and Mast, 2012). A possible explanation for these findings could be the shift in spatial attention that is associated with the displacement of the body in space. Passive self-motion around the earth-vertical axis has been shown to shift spatial attention in the direction of motion: leftward motion facilitated the processing of a dot presented on the left side of the screen or a tactile stimulus applied on the left side of the body, whereas the opposite pattern was found for rightward motion (Figliozzi et al., 2005). Such a shift in spatial attention could also influence the processing of spatially represented stimuli. For example, moving leftwards makes small numbers more accessible because spatial attention is shifted to the left side of the mental number line.

\section{COGNITIVE INFLUENCE ON VESTIBULAR PERCEPTION}

Interestingly, there is also an effect in the reverse direction: cognitive processes can change the perception of vestibular stimuli. To date, it is still widely believed that self-motion perception is determined by characteristics of sensory receptors, and it has been shown that vection induces subtle sensorimotor changes in arm movement control (Bringoux et al., 2012). Interestingly, selfmotion perception can be modulated by high-level visual input like seeing another person in motion (Lopez et al., 2013, see Deroualle and Lopez, 2014, this issue, for a review on vestibular information in social cognition). More surprisingly, Wertheim et al. (2001) showed that prior knowledge of motion can influence the perception of passive self-motion. Recently, Hartmann et al. (2012b) could demonstrate that processing small or larger numbers facilitated the detection of leftward or rightward rotation. Yet other studies have used mental imagery of visual motion, which also influences the perception of vestibular stimuli (Mast et al., 1999, 2001; Mertz and Lepecq, 2001). For example, mental imagery of self-motion by means of imagined vection stimuli can influence the perception of physical self-motion; recognition of target acceleration was improved when participants imagined themselves passively moving in the same direction, and, likewise, performance was impaired when the direction of imagined and perceived self-motion were incongruent (Mertz et al., 2000).

What needs to be more thoroughly investigated in future research is whether changes in thresholds have their origin at the level of sensitivity or at a later decision stage. Hartmann et al. (2013) could show that sensitivity in self-motion perception cannot be changed as a function of perceptual learning, and therefore, it is more likely that a bias rather than sensitivity is responsible for changes in thresholds. It is interesting that Rodionov et al. (2004) have shown that imagined body rotations can induce a typical nystagmus in healthy participants, and this findings suggests that imagined movements can penetrate the level of early oculomotor mechanisms. Gianna-Poulin et al. (2001), however, did not find a reduction of postrotatory nystagmus during imagined body tilts after prolonged yaw rotation. They conclude that velocity storage mechanisms are not malleable by cortical input. More research is needed to better investigate under which conditions and what kind of top-down processes can change oculomotor control. More specific knowledge about top-down influences on vestibular perception and vestibular reflexive responses may likely have a potential for application. For example, the use of cognitive procedures such as mental imagery training may be beneficial in vestibular rehabilitation (Lopez et al., 2011).

\section{BODY REPRESENTATION}

The sense we have of our own body, that we own it and have agency over it, that we can integrate our physical selves with our environment in functional ways, are sophisticated capacities that are often taken for granted. Head and Holmes (1911) proposed the terms body schema (related to proprioception and movement) and Schilder (1935) first coined the term body image (related to bodily awareness), and they described what our body feels like, and how we feel about our body. Ever since this terminology has been introduced there was ambiguity and confusion about what these capacities described. The current review relates to both proprioceptive capacity and bodily awareness. We will use the term body representation to collectively describe these capacities. Several clinical phenomena consistent with disruption of body representation were attenuated after CVS (for an overview on bodily disorders see de Vignemont, 2010, Table 1). These conditions include tactile extinction (Vallar et al., 1993; Kerkhoff et al., 2011; Schmidt et al., 2013), personal neglect (Cappa et al., 1987; Vallar et al., 1990), hemianesthesia (Vallar et al., 1990; Bottini et al., 2005), anosognosia (Cappa et al., 1987), somatoparaphrenia (Bisiach et al., 1991; Rode et al., 1992), macrosomatognosia (Rode et al., 2012) and phantom limb sensations (André et al., 2001; le Chapelain et al., 2001). Investigations into these phenomena have a long tradition, but only recently a few research groups began investigating potential effects of vestibular stimulation on tactile perception in healthy subjects. First, left cold $\mathrm{CVS}^{2}$ improved tactile perception in both

\footnotetext{
${ }^{2}$ Known to activate predominantly the right hemisphere (Miller and Ngo, 2007).
} 
hands (Ferrè et al., 2011, 2013a). Similar results were found when using left anodal and right cathodal $\mathrm{GVS}^{3}$ - tactile perception was bilaterally enhanced-while right anodal and left cathodal GVS ${ }^{4}$ as well as sham stimulation had no effects (Ferrè et al., 2013b). Second, tactile localization was affected by GVS. Namely, tactile localization on the hand dorsum was shifted in the proximal-distal axis toward the wrist. This localization bias was greater after right anodal and left cathodal GVS compared to left anodal and right cathodal GVS (Ferrè et al., 2013c). Third, Lopez et al. (2012c) used left cold, right warm CVS to investigate the influence of vestibular input on the body schema. Participants performed a tactile distance comparison and stimuli applied to the hand were judged to be longer during CVS when compared to sham stimulation. In a second experiment they showed that the perceived size of the hand increased during CVS with respect to sham stimulation, implying an enlarged somatorepresentation due to vestibular stimulation. However, this is in contrast to Ferrè et al. (2013c) who found no effects of GVS on this type of task. Moreover, Lopez et al. (2010) used the "rubber hand illusion" paradigm and they found an increased illusory ownership for the left rubber hand and illusory location of touch when applying left anodal and right cathodal GVS. No effects were found when sham stimulation or right anodal and left cathodal GVS were used. Interestingly, no influences on the "objective" proprioceptive drift were observed (Lopez et al., 2010, 2012a). These studies extend earlier clinical reports about the association of vestibular dysfunction and abnormal bodily sensations that have been identified over a century ago (Bonnier, 2009).

Influences of vestibular stimulation on tactile perception and body representation in healthy subjects and patients alike seem plausible given the anatomical overlap of vestibular and somatosensory networks (Lopez and Blanke, 2011; Lopez et al., 2012b). A recent fMRI study that applied tactile and CVS in the same subjects revealed important overlapping cortical activation in the dorsal posterior insula and the parietal operculum (zu Eulenburg et al., 2013b). Moreover, an EEG study assessing somatosensory-evoked potentials elicited by electrical left median nerve stimulation before and after left cold CVS found a bilaterally enhanced N80 component, presumably generated in the parietal operculum (Ferrè et al., 2012). More research is needed to better control for the specificity of vestibular stimulation, and how long its effects persist over time.

Recently, Ferrè et al. (2013a) and Bottini et al. (2013, this issue) argue that CVS exerts specific effects that can be interpreted as sensory signal management. By modulating other sensory modalities vestibular signals can help to flexibly adjust to changing information with respect to the relation between the body and the external world, and therefore better anticipate future motor and perceptual events. According to the authors, CVS activates specific cortico-subcortical networks linking vestibular and somatosensory processes. We think that this connection has far reaching consequences beyond the somatotopic representation in the brain. As we will see below some studies

${ }^{3}$ Known to activate predominantly the right hemisphere (Utz et al., 2010). ${ }^{4}$ Known to bilaterally activate vestibular cortical areas (Utz et al., 2010). suggest that vestibular information can alleviate pain, and we will also describe in more detail how it interfaces with affective processes.

\section{VESTIBULAR STIMULATION AND PAIN}

Parents often comfort and sooth infants, when they just hurt themselves, by carrying and rocking them, thus providing plenty of vestibular stimulation (for scientific evidence for the soothing effect of rocking see e.g., Korner and Thoman, 1972; Byrne and Horowitz, 1981). The soothing effect may not be attributed to vestibular influences alone but so far-vestibular perception and pain-have rarely been combined in investigations although other sensory cues such as visual (Moseley et al., 2008a; Longo et al., 2009; Ramachandran et al., 2009) and tactile (Moseley, 2008; Moseley et al., 2008b; Moseley and Wiech, 2009) cues have been revealed to impact pain. The insular cortex is recognized as an important interoceptive center (Craig, 2009) and recent experiments suggest it might also provide a possible interaction between vestibular and nociceptive processing (zu Eulenburg et al., 2013b).

Pain is about protection of the body and chronic pain is associated with a range of disrupted bodily representations (for reviews see e.g., Moseley et al., 2012; Haggard et al., 2013). That vestibular stimulation attenuates similar disruptions raises the tantalizing possibility that it may also modulate pain. In fact, Harris hypothesized already in 1999 that CVS could relieve pain without accompanying tissue damage (e.g., phantom pain in an amputated limb). He hypothesized that pain arises as consequence of a mismatch between afferent sensory information and (motor) intention and that vestibular stimulation may help to restore balance in shared brain areas (Harris, 1999). Although there is limitated empirical support for the mismatch theory (e.g., Wand et al., 2014), there are a few studies reporting on the beneficial effect of vestibular stimulation. The first account that CVS can alleviate pain comes from participants with amputations and phantom limb perception (André et al., 2001). All of 10 amputees with painful phantom limb perception reported temporary relief after CVS (through the replacement with a normal non-painful phantom limb). Similar reports were made in two paraplegic patients with painful phantom limb perception (le Chapelain et al., 2001). The authors argue that vestibular information aids in reconstructing the global body schema (André et al., 2001), pinpointing the interaction between body representation and pain in these patients.

Shared brain structures for nociceptive and vestibular information processing have been proposed (for a review see Balaban, 2011). Recent clinical studies show yet again encouraging findings. Two patients with thalamic pain syndrome were suffering from severe pain in the contralateral body side after stroke for several years showing little relief from medication. Cold water CVS of the left and the right ear showed an important decrease in pain ratings, while sham stimulation had no effect. When the procedure was repeated just once, the positive effects lasted for several weeks (Ramachandran et al., 2007a,b). Nine patients with central post-stroke pain (CPSP; McGeoch et al., 2008) and one patient with transverse myelitis of the cervical 
spinal cord who developed right-sided central pain (McGeoch and Ramachandran, 2008) received treatment with a similar CVS protocol. Again, overall pain ratings decreased significantly. Interestingly, these patients reported that pain relief was greatest in the upper body (face and arm) while there was only little relief for the lower body (leg). It has been hypothesized that the posterior insula and/or anterior cingulate cortex (ACC) play a key role in the neural underpinnings of pain alleviation induced by CVS. Vestibular stimulation activates the posterior insula, which in turn is proposed to inhibit the generation of pain in the ACC (Miller and Ngo, 2007; Ramachandran et al., 2007b; McGeoch and Ramachandran, 2008). This seems to be supported by the findings of a single-case study using MEG measurements before and after CVS revealing reduced ACC activation. This patient with CPSP reported decreased pain up to 4 days after treatment (McGeoch et al., 2009). Furthermore, results from three patients suggest that CVS can reduce pain only when the main vestibular cortical areas are spared (McGeoch et al., 2008; Rode et al., 2012). Given the low sample size in the studies reported above caution needs to be taken and the influence of potential biases will need to be controlled for in future research. In this context it is of interest that neurotransmitters can possibly help explain the beneficial effects of vestibular stimulation. Indeed, GVS was found to increase the release of GABA in rats (Samoudi et al., 2012) and gabapentin — a GABA analog — is a frequently prescribed drug to treat pain (e.g., neuropathic pain, Jensen et al., 2009).

Surprisingly, and to the best of our knowledge, there is only one study that has investigated whether vestibular stimulation can affect pain in healthy participants. Ferrè et al. (2013a) assessed tactile and pain thresholds in healthy participants before and after left-sided cold CVS. They showed that while tactile thresholds decrease, pain thresholds increased after stimulation, but no control condition was used, and the lack of a control intervention makes it hard to exclude diffuse noxious inhibitory control.

In sum, while these results are encouraging, more research with sound methodology (e.g., well-controlled studies that include sham conditions, randomized control studies) and greater sample size is needed. At this point it is still difficult to draw a conclusion whether the influences observed underlie a direct function or whether they are rather unspecific. Conceivable confounders may include stress (Saman et al., 2012), attentional or placebo effects. Moreover, future clinical studies need to clarify which chronic pain conditions can benefit from vestibular stimulation and which cannot. Moreover, which is the best vestibular stimulation protocol for which type of pain and what are the underlying neural underpinnings. While common vestibular and pain processing areas have been outlined, imaging studies yet need to assess possible structural changes due to vestibular stimulation. We hypothesize that vestibular stimulation can alleviate pain by contributing to ameliorate the impaired body schema and help restore the "body matrix" (Moseley et al., 2012). Thus, conditions like complex regional pain syndrome or chronic back pain, where disturbed body representations have been described (e.g., Moseley, 2005, 2008; Moseley et al., 2008a,b), should benefit the most. We even go on to speculate that other clinical conditions that involve disturbances of body representation such as Anorexia Nervosa (e.g., Garfinkel et al., 1978; Keizer et al., 2013) may profit as well. While Anorexia Nervosa has not yet been experimentally assessed and linked to vestibular stimulation, other mental disorders-outlined below-have been investigated. However, on this note, it is important to point out that a recent study that assessed the effect of CVS in participants suffering from body identity integrity disorder (BIID) was not able to significantly reduce the estrangement of the affected limb(s) (Lenggenhager et al., 2014). Against the background of publication bias, negative findings are informative and clearly indicate the need for well-controlled studies with sufficient sample size.

\section{AFFECTIVE PROCESSES AND DISORDERS}

Links between vestibular dysfunction, anxiety and panic disorders have been suggested for a long time (for an overview see Balaban and Jacob, 2001). Patients with a vestibular disorder have a higher probability of suffering from depression, anxiety and panic disorders (with and without agoraphobia) (Eagger et al., 1992; Godemann et al., 2004; Guidetti et al., 2008; Gazzola et al., 2009). Likewise, patients with a psychiatric disorder (such as anxiety or panic disorder) often report vestibular symptoms such as dizziness. A current model that explains the high comorbidity between psychiatric symptoms in vestibular disorders proposes that depression and anxiety are a reaction to the distress of living with vestibular dysfunctions (Jacob et al., 1996). This explanation does not provide any insights into the underlying mechanisms. Several studies concluded that patients with agoraphobic, panic or motion discomfort disorder have problems with multisensory integration (Yardley et al., 1994; Jacob et al., 1996, 1997). Vestibular patients rely predominantly on visual (Dieterich et al., 2007) and proprioceptive cues (Bles et al., 1984). Inadequate integration of visual and proprioceptive information may result in the fear of falling (space and motion discomfort) (Jacob et al., 1996). Interestingly, Viaud-Delmon et al. (2002) could show that participants with high trait anxiety also rely more on external visual cues in a visual-vestibular conflict task. The authors proposed that vestibular dysfunctions in high trait anxious participants may not affect low-level vestibular functions but rather involve problems with higher order cognitive integration of self-motion signals contributing to spatial cognition (Berthoz and Viaud-Delmon, 1999). However, previous studies show that low-level vestibular functions are also affected. Yardley et al. (1992) found an increased slow phase velocity of the VOR in high state anxious participants, which is an indicator for risk of dizziness. Studies in panic disorder patients have shown abnormal responses in postural stability and abnormal oculomotor functioning (Sklare et al., 1990; Redfern et al., 2007).

Taken together, epidemiological studies support a high comorbidity between vestibular and emotional disorders. However, the underlying neural mechanisms remain unclear. Although the limbic and prefrontal contributions to the processing of emotional information are well established, the influence of vestibular processes is not yet thoroughly understood. Recent evidence suggests that the interaction between vestibular functioning and 
emotion processing may underlie shared subcomponents of a common neural network (Preuss et al., 2014a).

\section{BRAINSTEM LINKS AND CORTICAL CONNECTIONS}

Several brain regions are commonly involved in vestibular and emotion processing (Yardley et al., 1999; Balaban and Jacob, 2001). Widespread vestibular-cortical projections may account for the comorbidity between the vestibular and psychiatric symptoms (Balaban et al., 2011; Lopez and Blanke, 2011; Gurvich et al., 2013). One key anatomical region in the brainstem is the parabrachial nucleus (PBN; Balaban and Thayer, 2001; Balaban, 2004). The PBN provides a direct link between the vestibular system and emotion processing, and it has bi-directional connections to the vestibular nuclei (Balaban, 2002, 2004; Balaban et al., 2011). Furthermore, the PBN network exerts reciprocal connections to the amygdala, hypothalamus, locus coeruleus and prefrontal cortex, which are all areas of the limbic system and have been associated with affective disorders (Schuerger and Balaban, 1999; Gorman et al., 2000; Balaban and Thayer, 2001). Yet other brainstem regions that have reciprocal connections with the vestibular nuclei are the raphe nuclei and the locus coeruleus. Both regions are involved in psychiatric conditions. The raphe nuclei send serotonergic and nonserotonergic projections to the vestibular nuclei (Kalén et al., 1985; Halberstadt and Balaban, 2006) and axon correlates to the central amygdaloid nucleus, suggesting a modulating effect of vestibular pathways on affective control (Halberstadt and Balaban, 2006). The locus coeruleus sends noradrenergic projections to the vestibular nuclei (Schuerger and Balaban, 1999) and also responds to vestibular stimulation (Manzoni et al., 1989).

Within the vestibular network, the ACC has been considered as the bridge between vestibular-sensorimotor areas and the affect divisions of the prefrontal cortex that entail motivational states (Bush et al., 2000). The insular cortex is the core region that receives input from the vestibular nuclei in the brain stem (Akbarian et al., 1994). The prefrontal cortex plays a more indirect role in the processing of vestibular information and suppresses the impact of irrelevant sensory information and regulates incoming sensory stimulation that can overwhelm cognitive capacities (see for example Yamaguchi and Knight, 1990, 1991; Rule et al., 2002; Angrilli et al., 2008). For example, coherent fullfield visual motion stimuli elicit the sensation of self-motion such as the illusory feeling of motion when sitting in the stationary train while it is only the neighboring train that pulls out of the station in the direction opposite to the felt motion. However, people react differently to full-field motion stimuli, and in laboratory experiments additional tasks can weaken the strength of vection (Seno et al., 2011). Prefrontal regions may exert their influence over the vestibular cortical regions through its indirect connection with the premotor areas and the temporal lobes (Damasio and Anderson, 2003). However, the prefrontal cortex does not only regulate incoming sensory information but it also serves the regulation of emotions. Indeed, Carmona et al. (2009) proposed a conceptual model, integrating both mechanisms and the role of vestibular information. The first mechanism ("sensorimotor-affective mechanism") involves the dense interconnection of the vestibular sensory areas and the anterior cingulate gyrus and the prefrontal cortex. Frontal regions (via motor areas and anterior cingulate gyrus) exert a regulatory influence on vestibular areas and attenuate sensory stimulation as described in the example given above (Carmona et al., 2009, see also Akbarian et al., 1994; Nishiike et al., 2000). The second mechanism ("autonomic-affective mechanism") involves the direct link between the vestibular nuclei with limbic structures. Carmona et al. (2009) propose that the frontal lobes exert an inhibitory control over the vestibular nuclei in the brainstem. As a consequence, intense negative stressors (triggered though vestibular dysfunctions, dizziness, disorientation, motion sickness etc.) burden frontal resources, resulting in diminished capacity to allocate resources for attenuating activation in posterior sensory and autonomic regions (e.g., the insula and the temporal lobe). This leads to difficulties in maintaining sensorimotor coordination in balance and regulating arousal.

\section{VESTIBULAR STIMULATION, AFFECT AND LATERALITY}

Recent evidence suggests that vestibular stimulation can have a positive effect on affect and psychiatric disorders. Dodson (2004) showed in a single case study that left cold CVS exerts a beneficial effect on manic symptom severity. The positive effect of CVS on mania can be attributed to an activation of right hemispheric structures. Levine et al. (2012) showed an increase in bilateral frontal and central alpha EEG band activation in three patients suffering from a schizoaffective disorder. They proposed that left cold CVS can have a short lived beneficial effect on manic delusions and insight of illness that appear in mania and other types of psychoses (i.e., schizophrenia).

Hemispheric laterality in the processing of emotions and affective information has been proposed for many years. Lateralization of vestibular processes, however, is relatively new and has come to light in the last years. Dieterich et al. (2003) could show a dominance of vestibular cortical function in the non-dominant hemisphere. Several studies reported greater right than left hemispheric activation in the vestibular cortex (Bottini et al., 1994, 2001; Dieterich et al., 1998, 2003; Lobel et al., 1998; Fasold et al., 2002; Kahane et al., 2003; Schlindwein et al., 2008). Models of hemispheric lateralization of emotions have proposed that the hemispheres process emotional information differently ("valencespecific hypothesis") (Tucker, 1981; Davidson and Fox, 1982; Davidson, 1992).

Although conversely discussed, the valence-specific hypothesis assumes that negative emotions are processed in the right hemisphere whereas positive emotions are processed in the left hemisphere. Pettigrew and Miller (1998) proposed a model for bipolar disorder ("sticky switch model"), which views mania as the endpoint of relative left hemispheric activation and depression as the endpoint of relative right hemispheric activation. In order to examine this hypothesis, Miller et al. (2000, 2003) used a binocular rivalry task in which two competing images are presented to each eye separately. This leads to an alternating perception of each image mediated by alternating hemispheric activation (interhemispheric switching). The author reported a slower alternation rate in patients with bipolar disorder leading to the conclusion of a slow interhemispheric switching in these patients-the brain becomes "stuck" in one of two states (Miller 
et al., 2003). Interestingly, CVS can be used to effectively modulate the alternation rate in binocular rivalry (Miller et al., 2000).

The findings of these studies all lead to the conclusion that vestibular stimulation could be a potential therapeutic treatment in mania and depression. Left cold ear CVS, through its activation of the right hemisphere, was proposed to reduce manic symptom severity whereas right cold ear CVS, through its activation of the left hemisphere, was proposed to reduce symptoms in depression. Since then, clinical evidence has indeed shown a beneficial effect of left cold CVS on manic symptom severity (Dodson, 2004; Levine et al., 2012). So far, only one study investigated the effect of CVS in major depression (Ried and Aviles, 2007). Patients suffering from a major depressive disorder show a bilateral decrease in slow phase velocity of the nystagmus following $30^{\circ} \mathrm{C}$ and $44^{\circ} \mathrm{C}$ CVS. Unfortunately, changes in mood were not assessed. In addition to clinical findings, a recent study could show that CVS has mood and affect regulating effects in healthy participants (Preuss et al., 2014a). Preuss et al., 2014b could show that left cold CVS decreases affective control whereas right cold CVS increased affective control for positive stimuli in an affective Go/NoGo task. The authors concluded that the change in affective control is due to an activation of the underlying emotional network. Furthermore, a recent study could show that CVS can also influence decision outcome in purchase decisionmaking. Left cold CVS decreased the probability of purchasing a product and also desirability of the products (Preuss et al., 2014b). McKay et al. (2013) could show that cold CVS of the left ear decreases unrealistic optimism in healthy subjects. Unrealistic optimism is a bias that causes a person to believe that he or she is less at risk of experiencing negative events (such as illnesses). Hence, unrealistic optimism represents some sort of delusion or subclinical anosognosia in healthy subjects. Indeed, the authors conclude that both unrealistic optimism and anosognosia (see also Cappa et al., 1987) share the same underlying mechanisms. Future studies should thus further investigate the effect of CVS in affective disorders as CVS might regulate mood and affect in major depression and mania but also give insight into delusion and illness denial. Vestibular stimulation by non-invasive methods, and its potential use in the treatment of the conditions outlined above is by far not exploited.

\section{DISCUSSION}

Activation of the vestibular system leads to widespread activity in different cortical areas but the extent of all the functions the vestibular network is involved in are not yet clear. We have described three streams of research, which have in common that they can be modulated by vestibular information. None of these areas belongs to traditional domains of vestibular research like postural control, VOR, and self-motion perception. Therefore, the question about the purpose of vestibular information in these tasks is by all means justified. Before searching for answers to this question, one needs to take a step back and wonder why the answers are not yet known already. Several conceivable explanations can be brought forward. First, it is clear that the paucity of knowledge in a given field is proportional to the amount of research carried out. The number of 24,163 articles shows up in PubMed with the term "vestibular" in the title or abstract. In comparison, there are 261,164 with the term "visual" (PubMed, October 18th, 2013, the results are corrected for contributions with both terms). This means that there are 10.8 times more articles published in the visual domain. Indeed, the visual system processes a wider range of different stimuli such as motion, color, orientation, form and so forth, and to date, the knowledge of cortical neurophysiology is by far better understood when compared to the vestibular domain. It is a relatively recent trend that vestibular information has gained some more attention based on growing evidence of its involvement in tasks that are seemingly remote from known vestibular functions. Second, the lack of knowledge is - at least in part-caused by the experimental effort that is necessary to carry out vestibular experiments. For example, motion devices that are capable of providing well-controlled vestibular stimuli do not belong to the standard equipment of perception research laboratories. They are expensive and often require labor intense software development for machine control. Moreover, true motion cannot be applied in combination with most neuroimaging devices, and the use of techniques like CVS and GVS entail problems of inducing sensory conflicts (e.g., during CVS participants are in a pitchedback position and receive a stimulation of the canals while the otoliths signal no change in posture). A promising new technique for vestibular research is functional near-infrared spectroscopy (fNIRS) because participants can be tested in different body positions as compared to fMRI studies, which only allow measurements in the supine position. A recent fNIRS study by Karim et al. (2013) used CVS and confirmed previous fMRI and PET activation and lateralization patterns on the cortical surface. Last but not least, it is puzzling that sporadic research findings in vestibular science are not followed up more rigorously. A case in point is the work by Sauvan and Peterhans (1995) and Sauvan (1999). They have shown that a proportion of neurons in occipital area V2 shift their orientation specificity from retinal to gravity related coordinates during static roll tilts. This finding brings up fundamental questions about multisensory integration and the level at which otolith information is fed into the visual system to achieve space constancy. The striking phenomenon of a perceptually upright world when the head is tilted is not understood, but, currently, there seems to be relatively little interest in a thorough investigation of this fundamental spatial ability, also among the large community of vision scientists. To our knowledge, no follow-up study has been conducted since Peterhans and Sauvan's work, and only few articles made reference to their work.

What are the functions vestibular information can have in tasks that are seemingly remote from known functions like selfmotion perception or postural control? First of all, the vestibular system establishes a frame of reference for spatial orientation. It provides information about the spatial relation of the self with respect to the world. Bringing the gravito-inertial force (GIF) vector in line with the body's main axis is the set value in any type of behavior. The GIF is an allocentric cue and its perception connects egocentric body-based coordinates with external world coordinates. Sudden and unintended deviations from the GIF are rapidly compensated for by postural adjustments. In case of obstacles a continued and undesired deviation from 
the GIF indicates vulnerability and therefore distress, which is a warning signal and thus reinforces the motivation to initiate a change in posture. Disequilibrium is a stressor indicating an unintended mismatch between frames of reference. This is where the interface between balance and affective processesboth phylogenetically old mechanisms_comes into play. Affective processes signal importance, and trigger a more or less elaborated coping behavior, depending on the organism's capacities. In this sense, postural reflexes involve more than just a change in body posture. Disequilibrium and falls are a threat to the organism that triggers an affective response. In real life, it is possible that the body's immediate and fast reflex loops precede the affective response such as when we miss a step on the stairs without actually falling. We start to feel the increase in heart beat just after having successfully avoided a fall. The existence of this vestibulo-affective interaction will unfold to its maximum when immediate correction of posture is impeded. Affect and body motion are interconnected, and future research will be needed to explore the underlying mechanisms. Moreover, a bodily representation of the self, for example, serves as a reliable tool for mentally simulating future events without having to act them out. This representation can trigger affective responses because the representation constitutes the self. Vividly imagining a fall can cause fear and affective responses, just as in the real world walking down a steep slope on a frozen street inevitably causes fear of falling. Mental imagery does not only draw in an off-line mode on sensory representations but it also involves affective processes depending on the relevance of the imagined content.

This review highlighted the role of vestibular information beyond guiding the body through the physical world. Cognitive processes such as mental spatial transformations or the processing of spatially represented information is nested with the processing of vestibular information. These vestibular interactions with higher-order spatial cognition could be based on the reference frame that the vestibular system provides the brain with. The otolith organs constantly update our body position in space with respect to gravity and this allows for representing the outside world within defined spatial vectors (horizontal, vertical, and transversal axis). The same spatial reference system manifests itself in cognitive tasks. According to the grounded cognition theory, space as a more concrete domain is used to structure, represent, and understand abstract concepts such as number magnitudes or temporal events that cannot be experienced directly through our senses (e.g., Lakoff and Johnson, 1980; Boroditsky, 2000; Gallese and Lakoff, 2005; Barsalou, 2008).

The vestibular system is a phylogenetically old structure that is nested and intertwined with subcortical and cortical structures. On the one hand, some reflex arcs can be considered vestigial such as ocular counterrolling because it does not fully counteract the impact of head tilts on the retinal image. On the other hand, however, the same efferent signal driving ocular counterrolling may be involved in other processes such as determining the gain of the visual field influence on the perception of the visual vertical as proposed by Bischof (1974). The multiple connections with other systems make it extremely complex to tease apart when and how vestibular input affects the processing of other modalities or affective responses. It is interesting that the vestibular system alone might be less plastic when compared to other sensory systems (Hartmann et al., 2013). Merfeld (2012) pointed out that vestibular organs appeared very early in evolutionary history and have remained relatively unchanged. It is therefore conceivable that an increase in vestibular sensitivity as a result of perceptual learning could have negative side effects such as motion sickness or an exaggerated response to small accelerations, for example during transport, and changes in sensitivity might affect all other modalities that are connected to the vestibular system. In fact, there is evidence that the vestibular system has numerous connections and overlaps with other functional networks. Based on recent research in spatial cognition, body representation and affective processes we presented an overview that will hopefully stimulate and contribute to future research in vestibular science.

\section{ACKNOWLEDGMENTS}

The research leading to these results received financial support from the Swiss National Science Foundation (SNF Sinergia and ProDoc projects awarded to Fred W. Mast, postdoctoral fellowship awarded to Luzia Grabherr). We thank Lorimer Moseley for valuable advice and Gerda Wyssen for her help with the preparation of the manuscript.

\section{REFERENCES}

Akbarian, S., Grüsser, O. J., and Guldin, W. O. (1994). Corticofugal connections between the cerebral cortex and brainstem vestibular nuclei in the macaque monkey. J. Comp. Neurol. 339, 421-437. doi: 10.1002/cne.903390309

André, J. M., Martinet, N., Paysant, J., Beis, J. M., and Le Chapelain, L. (2001). Temporary phantom limbs evoked by vestibular caloric stimulation in amputees. Neuropsychiatry Neuropsychol. Behav. Neurol. 14, 190-196.

Angrilli, A., Bianchin, M., Radaelli, S., Bertagnoni, G., and Pertile, M. (2008). Reduced startle reflex and aversive noise perception in patients with orbitofrontal cortex lesions. Neuropsychologia 46, 1179-1184. doi: 10.1016/j. neuropsychologia.2007.10.018

Arzy, S., Collette, S., Ionta, S., Fornari, E., and Blanke, O. (2009). Subjective mental time: the functional architecture of projecting the self to past and future. Eur. J. Neurosci. 30, 2009-2017. doi: 10.1111/j.1460-9568.2009.06974.x

Bächtold, D., Baumann, T., Sandor, P., Kritos, M., Regard, M., and Brugger, P. (2001). Spatial- and verbal-memory improvement by cold-water caloric stimulation in healthy subjects. Exp. Brain Res. 136, 128-132. doi: 10. 1007/s002210000588

Baek, J. H., Zheng, Y., Darlington, C. L., and Smith, P. F. (2010). Evidence that spatial memory deficits following bilateral vestibular deafferentation in rats are probably permanent. Neurobiol. Learn. Mem. 94, 402-413. doi: 10.1016/j.nlm. 2010.08.007

Balaban, C. D. (2002). Neural substrates linking balance control and anxiety. Physiol. Behav. 77, 469-475. doi: 10.1016/s0031-9384(02)00935-6

Balaban, C. D. (2004). Projections from the parabrachial nucleus to the vestibular nuclei: potential substrates for autonomic and limbic influences on vestibular responses. Brain Res. 996, 126-137. doi: 10.1016/j.brainres.2003. 10.026

Balaban, C. D. (2011). Migraine, vertigo and migrainous vertigo: links between vestibular and pain mechanisms. J. Vestib. Res. 21, 315-321. doi: 10.3233/VES2011-0428

Balaban, C. D., and Jacob, R. G. (2001). Background and history of the interface between anxiety and vertigo. J. Anxiety Disord. 15, 27-51. doi: 10.1016/s08876185(00)00041-4

Balaban, C. D., Jacob, R. G., and Furman, J. M. (2011). Neurologic bases for comorbidity of balance disorders, anxiety disorders and migraine: neurotherapeutic implications. Expert Rev. Neurother. 11, 379-394. doi: 10.1586/ ern.11.19 
Balaban, C. D., and Thayer, J. F. (2001). Neurological bases for balance-anxiety links. J. Anxiety Disord. 15, 53-79. doi: 10.1016/s0887-6185(00)00042-6

Barsalou, L. W. (2008). Grounded cognition. Annu. Rev. Psychol. 59, 617-645. doi: 10.1146/annurev.psych.59.103006.093639

Berthoz, A., and Viaud-Delmon, I. (1999). Multisensory integration in spatial orientation. Curr. Opin. Neurobiol. 9, 708-712. doi: 10.1016/s0959-4388(99) 00041-0

Besnard, S., Machado, M. L., Vignaux, G., Boulouard, M., Coquerel, A., Bouet, V., et al. (2012). Influence of vestibular input on spatial and nonspatial memory and on hippocampal NMDA receptors. Hippocampus 22, 814-826. doi: 10. 1002/hipo.20942

Bischof, N. (1974). "Optic-vestibular orientation to the vertical," in Vestibular System Part 2: Psychophysics, Applied Aspects and General Interpretations, eds A. J. Benson, N. Bischof, W. E. Collins, A. R. Fregly, A. Graybiel, F. E. Guedry and K. Schaefer (Berlin, Heidelberg: Springer), 155-190.

Bisdorff, A. R., Wolsley, C. J., Anastasopoulos, D., Bronstein, A. M., and Gresty, M. A. (1996). The perception of body verticality (subjective postural vertical) in peripheral and central vestibular disorders. Brain 119, 1523-1534. doi: 10. 1093/brain/119.5.1523

Bisiach, E., Rusconi, M. L., and Vallar, G. (1991). Remission of somatoparaphrenic delusion through vestibular stimulation. Neuropsychologia 29, 10291031. doi: 10.1016/0028-3932(91)90066-h

Bles, W., Jong, J. M. V., and Wit, G. D. (1984). Somatosensory compensation for loss of labyrinthine function. Acta Otolaryngol. 97, 213-221. doi: 10. 3109/00016488409130982

Bonnier, P. (2009). Asomatognosia P. Bonnier. L'aschematie. Revue Neurol 1905;13:605-609. Epilepsy Behav. 16, 401-403. doi: 10.1016/j.yebeh.2009.09.020

Boroditsky, L. (2000). Metaphoric structuring: understanding time through spatial metaphors. Cognition 75, 1-28. doi: 10.1016/s0010-0277(99)00073-6

Bottini, G., Gandola, M., Sedda, A., and Ferrè, E. R. (2013). Caloric vestibular stimulation: interaction between somatosensory system and vestibular apparatus. Front. Integr. Neurosci. 7:66. doi: 10.3389/fnint.2013.00066

Bottini, G., Karnath, H. O., Vallar, G., Sterzi, R., Frith, C. D., Frackowiak, R. S. J., et al. (2001). Cerebral representations for egocentric space: functionalanatomical evidence from caloric vestibular stimulation and neck vibration. Brain 124(Pt. 6), 1182-1196. doi: 10.1093/brain/124.6.1182

Bottini, G., Paulesu, E., Gandola, M., Loffredo, S., Scarpa, P., Sterzi, R., et al. (2005). Left caloric vestibular stimulation ameliorates right hemianesthesia. Neurology 65, 1278-1283. doi: 10.1212/01.wnl.0000182398.14088.e8

Bottini, G., Sterzi, R., Paulesu, E., Vallar, G., Cappa, S. F., Erminio, F., et al. (1994). Identification of the central vestibular projections in man: a positron emission tomography activation study. Exp. Brain Res. 99, 164-169. doi: 10. 1007/bf00241421

Brandt, T., Glasauer, S., Stephan, T., Bense, S., Yousry, T. A., Deutschländer, A., et al. (2002). Visual-vestibular and visuovisual cortical interaction. Ann. N Y Acad. Sci. 956, 230-241. doi: 10.1111/j.1749-6632.2002.tb02822.x

Brandt, T., Schautzer, F., Hamilton, D. A., Brüning, R., Markowitsch, H. J., Kalla, R., et al. (2005). Vestibular loss causes hippocampal atrophy and impaired spatial memory in humans. Brain 128, 2732-2741. doi: 10.1093/brain/awh617

Bremmer, F., Klam, F., Duhamel, J. R., Ben Hamed, S., and Graf, W. (2002). Visualvestibular interactive responses in the macaque ventral intraparietal area (VIP). Eur. J. Neurosci. 16, 1569-1586. doi: 10.1046/j.1460-9568.2002.02206.x

Bringoux, L., Lepecq, J.-C., and Danion, F. (2012). Does visually induced selfmotion affect grip force when holding an object? J. Neurophysiol. 108, 16851694. doi: $10.1152 /$ jn. 00407.2012

Bringoux, L., Mezey, L. E., Faldon, M., Gresty, M. A., and Bronstein, A. M. (2007). Influence of pitch tilts on the perception of gravity-referenced eye level in labyrinthine defective subjects. Neuropsychologia 45, 350-356. doi: 10.1016/j. neuropsychologia.2006.05.028

Bringoux, L., Schmerber, S., Nougier, V., Dumas, G., Barraud, P. A., and Raphel, C. (2002). Perception of slow pitch and roll body tilts in bilateral labyrinthine-defective subjects. Neuropsychologia 40, 367-372. doi: 10. 1016/s0028-3932(01)00103-8

Bronstein, A. M. (1999). The interaction of otolith and proprioceptive information in the perception of verticality: the effects of labyrinthine and CNS disease. Ann. N Y Acad. Sci. 871, 324-333. doi: 10.1111/j.1749-6632.1999.tb09195.x

Bush, G., Luu, P., and Posner, M. I. (2000). Cognitive and emotional influences in anterior cingulate cortex. Trends Cogn. Sci. 4, 215-222. doi: 10.1016/s13646613(00)01483-2
Byrne, J. M., and Horowitz, F. D. (1981). Rocking as a soothing intervention: the influence of direction and type of movement. Infant Behav. Dev. 4, 207-218. doi: $10.1016 / \mathrm{s} 0163-6383(81) 80024-0$

Candidi, M., Micarelli, A., Viziano, A., Aglioti, S. M., Minio Paluello, I., and Alessandrini, M. (2013). Impaired mental rotation in benign paroxysmal positional vertigo and acute vestibular neuritis. Front. Hum. Neurosci. 7:783. doi: 10. 3389/fnhum.2013.00783

Cappa, S., Sterzi, R., Vallar, G., and Bisiach, E. (1987). Remission of hemineglect and anosognosia during vestibular stimulation. Neuropsychologia 25, 775-782. doi: 10.1016/0028-3932(87)90115-1

Carmona, J. E., Holland, A. K., and Harrison, D. W. (2009). Extending the functional cerebral systems theory of emotion to the vestibular modality: a systematic and integrative approach. Psychol. Bull. 135, 286-302. doi: 10. 1037/a0014825

Corballis, M. C., Nagourney, B. A., Shetzer, L. I., and Stefanatos, G. (1978). Mental rotation under head tilt: factors influencing the location of the subjective reference frame. Percept. Psychophys. 24, 263-273. doi: 10.3758/bf0320 6098

Corballis, M. C., Zbrodoff, J., and Roldan, C. E. (1976). What's up in mental rotation? Percept. Psychophys. 19, 525-530.

Craig, A. D. (2009). How do you feel-now? the anterior insula and human awareness. Nat. Rev. Neurosci. 10, 59-70. doi: 10.1038/nrn2555

Dalecki, M., Dern, S., and Steinberg, F. (2013). Mental rotation of a letter, hand and complex scene in microgravity. Neurosci. Lett. 533, 55-59. doi: 10.1016/j.neulet. 2012.11.002

Damasio, A. R., and Anderson, S. W. (2003). "The frontal lobes," in Clinical Neuropsychology, eds K. M. Heilman and E. Valenstein (4th Edn.) (New York: Oxford Press), 417-465.

Davidson, R. J. (1992). Anterior cerebral asymmetry and the nature of emotion. Brain Cogn. 20, 125-151. doi: 10.1016/0278-2626(92)90065-t

Davidson, R. J., and Fox, N. A. (1982). Asymmetrical brain activity discriminates between positive and negative affective stimuli in human infants. Science 218, 1235-1237. doi: 10.1126/science.7146906

de Vignemont, F. (2010). Body schema and body image-Pros and cons. Neuropsychologia 48, 669-680. doi: 10.1016/j.neuropsychologia.2009.09.022

Deroualle, D., and Lopez, C. (2014). Towards a vestibular contribution to social cognition. Front. Integr. Neurosci. 8:16. doi: 10.3389/fnint.2014.00016

Dieterich, M., Bauermann, T., Best, C., Stoeter, P., and Schlindwein, P. (2007). Evidence for cortical visual substitution of chronic bilateral vestibular failure (an fMRI study). Brain 130(Pt. 8), 2108-2116. doi: 10.1093/brain/ awm 130

Dieterich, M., Bense, S., Lutz, S., Drzezga, A., Stephan, T., Bartenstein, P., et al. (2003). Dominance for vestibular cortical function in the non-dominant hemisphere. Cereb. Cortex 13, 994-1007. doi: 10.1093/cercor/13.9.994

Dieterich, M., Bucher, S. F., Seelos, K. C., and Brandt, T. (1998). Horizontal or vertical optokinetic stimulation activates visual motion-sensitive, ocular motor and vestibular cortex areas with right hemispheric dominance. An fMRI study. Brain 121(Pt. 8), 1479-1495. doi: 10.1093/brain/121.8.1479

Dilda, V., MacDougall, H. G., Curthoys, I. S., and Moore, S. T. (2012). Effects of galvanic vestibular stimulation on cognitive function. Exp. Brain Res. 216, 275 285. doi: 10.1007/s00221-011-2929-z

Dodson, M. J. (2004). Vestibular stimulation in mania: a case report. J. Neurol. Neurosurg. Psychiatry 75, 168-169.

Eagger, S., Luxon, L. M., Davies, R. A., Coelho, A., and Ron, M. A. (1992). Psychiatric morbidity in patients with peripheral vestibular disorder: a clinical and neuro-otological study. J. Neurol. Neurosurg. Psychiatry 55, 383-387. doi: 10. 1136/jnnp.55.5.383

Ebata, S., Sugiuchi, Y., Izawa, Y., Shinomiya, K., and Shinoda, Y. (2004). Vestibular projection to the periarcuate cortex in the monkey. Neurosci. Res. 49, 55-68. doi: 10.1016/j.neures.2004.01.012

Falconer, C. J., and Mast, F. W. (2012). Balancing the mind. Exp. Psychol. 59, 332339. doi: 10.1027/1618-3169/a000161

Fasold, O., Von Brevern, M., Kuhberg, M., Ploner, C. J., Villringer, A., Lempert, T., et al. (2002). Human vestibular cortex as identified with caloric stimulation in functional magnetic resonance imaging. Neuroimage 17, 1384-1393. doi: 10. 1006/nimg.2002.1241

Ferrè, E. R., Bottini, G., and Haggard, P. (2011). Vestibular modulation of somatosensory perception. Eur. J. Neurosci. 34, 1337-1344. doi: 10.1111/j.14609568.2011.07859.x 
Ferrè, E. R., Bottini, G., and Haggard, P. (2012). Vestibular inputs modulate somatosensory cortical processing. Brain Struct. Funct. 217, 859-864. doi: 10. 1007/s00429-012-0404-7

Ferrè, E. R., Bottini, G., Iannetti, G. D., and Haggard, P. (2013a). The balance of feelings: vestibular modulation of bodily sensations. Cortex 49, 748-758. doi: 10 . 1016/j.cortex.2012.01.012

Ferrè, E. R., Day, B. L., Bottini, G., and Haggard, P. (2013b). How the vestibular system interacts with somatosensory perception: a sham-controlled study with galvanic vestibular stimulation. Neurosci. Lett. 550, 35-40. doi: 10.1016/j.neulet. 2013.06.046

Ferrè, E. R., Vagnoni, E., and Haggard, P. (2013c). Vestibular contributions to bodily awareness. Neuropsychologia 51, 1445-1452. doi: 10.1016/j.neuropsychologia. 2013.04.006

Figliozzi, F., Guariglia, P., Silvetti, M., Siegler, I., and Doricchi, F. (2005). Effects of vestibular rotatory accelerations on covert attentional orienting in vision and touch. J. Cogn. Neurosci. 17, 1638-1651. doi: 10.1162/089892905774597272

Gallese, V., and Lakoff, G. (2005). The Brain's concepts: the role of the Sensorymotor system in conceptual knowledge. Cogn. Neuropsychol. 22, 455-479. doi: 10.1080/02643290442000310

Garfinkel, P. E., Moldofsky, H., Gamer, D. H., Stancer, H. C., and Coscina, D. V. (1978). Body awareness in anorexia nervosa: disturbances in "body image" and "satiety". Psychosom. Med. 40, 487-498. doi: 10.1097/00006842-19781000000004

Gaunet, F., and Berthoz, A. (2000). Mental rotation for spatial environment recognition. Cogn. Brain Res. 9, 91-102. doi: 10.1016/s0926-6410(99) 00038-5

Gazzola, J. M., Aratani, M. C., Doná, F., Macedo, C., Fukujima, M. M., Ganança, M. M., et al. (2009). Factors relating to depressive symptoms among elderly people with chronic vestibular dysfunction. Arq. Neuropsiquiatr. 67, 416-422. doi: 10 1590/s0004-282x2009000300009

Gianna-Poulin, C. C., Voelker, C. C., Erickson, B., and Black, O. F. (2001). Can imaginary head tilt shorten postrotatory nystagmus? Exp. Brain Res. 139, 503506. doi: 10.1007/s002210100781

Godemann, F., Linden, M., Neu, P., Heipp, E., and Dörr, P. (2004). A prospective study on the course of anxiety after vestibular neuronitis. J. Psychosom. Res. 56, 351-354. doi: 10.1016/s0022-3999(03)00079-5

Gorman, J. M., Kent, J. M., Sullivan, G. M., and Coplan, J. D. (2000). Neuroanatomical hypothesis of panic disorder, revised. Am. J. Psychiat. 157, 493-505. doi: 10 1176/appi.ajp.157.4.493

Grabherr, L., Cuffel, C., Guyot, J.-P., and Mast, F. W. (2011). Mental transformation abilities in patients with unilateral and bilateral vestibular loss. Exp. Brain Res. 209, 205-214. doi: 10.1007/s00221-011-2535-0

Grabherr, L., Karmali, F., Bach, S., Indermaur, K., Metzler, S., and Mast, F. W. (2007). Mental own-body and body-part transformations in microgravity. J. Vestib. Res. 17, 279-287.

Grüsser, O., Pause, M., and Schreiter, U. (1990). Localization and responses of neurones in the parieto-insular vestibular cortex of awake monkeys (Macaca fascicularis). J. Physiol. 430, 537-557.

Gu, Y., Deangelis, G. C., and Angelaki, D. E. (2007). A functional link between area MSTd and heading perception based on vestibular signals. Nat. Neurosci. 10, 1038-1047. doi: 10.1038/nn1935

Guidetti, G., Monzani, D., Trebbi, M., and Rovatti, V. (2008). Impaired navigation skills in patients with psychological distress and chronic peripheral vestibular hypofunction without vertigo. Acta Otorhinolaryngol. Ital. 28, 21-25.

Gurvich, C., Maller, J. J., Lithgow, B., Haghgooie, S., and Kulkarni, J. (2013). Vestibular insights into cognition and psychiatry. Brain Res. 1537, 244-259. doi: 10.1016/j.brainres.2013.08.058

Haggard, P., Iannetti, G. D., and Longo, M. R. (2013). Spatial sensory organization and body representation in pain perception. Curr. Biol. 23, R164-R176. doi: 10. 1016/j.cub.2013.01.047

Halberstadt, A. L., and Balaban, C. D. (2006). Serotonergic and nonserotonergic neurons in the dorsal raphe nucleus send collateralized projections to both the vestibular nuclei and the central amygdaloid nucleus. Neuroscience 140, 10671077. doi: 10.1016/j.neuroscience.2006.02.053

Harris, A. J. (1999). Cortical origin of pathological pain. Lancet 354, 1464-1466. doi: 10.1016/s0140-6736(99)05003-5

Hartmann, M., Farkas, R., and Mast, F. W. (2012a). Self-motion perception influences number processing: evidence from a parity task. Cogn. Process. 13, 189-192. doi: 10.1007/s10339-012-0484-6
Hartmann, M., Furrer, S., Herzog, M. H., Merfeld, D. M., and Mast, F. W. (2013) Self-motion perception training: thresholds improve in the light but not in the dark. Exp. Brain Res. 226, 231-240. doi: 10.1007/s00221-013-3428-1

Hartmann, M., Grabherr, L., and Mast, F. W. (2012b). Moving along the mental number line: interactions between whole-body motion and numerical cognition. J. Exp. Psychol. Hum. Percept. Perform. 38, 1416-1427. doi: 10. 1037/a0026706

Hartmann, M., and Mast, F. W. (2012). Moving along the mental time line influences the processing of future related words. Conscious. Cogn. 23, 15581562. doi: 10.1016/j.concog.2012.06.015

Head, H., and Holmes, G. (1911). Sensory disturbances from cerebral lesions. Brain 34, 102-254. doi: 10.1093/brain/34.2-3.102

Hubbard, E. M., Piazza, M., Pinel, P., and Dehaene, S. (2005). Interactions between number and space in parietal cortex. Nat. Rev. Neurosci. 6, 435-448. doi: 10. 1038/nrn1684

Hüfner, K., Hamilton, D. A., Kalla, R., Stephan, T., Glasauer, S., Ma, J., et al. (2007). Spatial memory and hippocampal volume in humans with unilateral vestibular deafferentation. Hippocampus 17, 471-485. doi: 10.1002/hipo.20283

Hüfner, K., Stephan, T., Hamilton, D. A., Kalla, R., Glasauer, S., Strupp, M., et al. (2009). Gray-matter atrophy after chronic complete unilateral vestibular deafferentation. Ann. N Y Acad. Sci. 1164, 383-385. doi: 10.1111/j.1749-6632. 2008.03719.x

Isaac, A., Marks, D. F., and Russell, D. G. (1986). An instrument for assessing imagery of movement: the Vividness of Movement Imagery Questionnaire (VMIQ). J. Ment. Imagery 10, 23-30.

Jacob, R. G., Furman, J. M., and Perel, J. M. (1996). "Panic, phobia and vestibular dysfunction," in Vestibular Autonomic Regulation, eds B. J. Yates and A. D. Miller (Boca Raton, FL: CRC Press), 197-227.

Jacob, R. G., Furman, J. M., Durrant, J. D., and Turner, S. M. (1997). Surface dependence: a balance control strategy in panic disorder with agoraphobia. Psychosom. Med. 59, 323-330. doi: 10.1097/00006842-199705000-00016

Jensen, T. S., Madsen, C. S., and Finnerup, N. B. (2009). Pharmacology and treatment of neuropathic pains. Curr. Opin. Neurol. 22, 467-474. doi: 10. 1097/wco.0b013e3283311e13

Just, M. A., Carpenter, P. A., Keller, T. A., Emery, L., Zajac, H., and Thulborn, K. R. (2001). Interdependence of non-overlapping cortical systems in dual cognitive tasks. Neuroimage 14, 417-426. doi: 10.1006/nimg.2001.0826

Kahane, P., Hoffmann, D., Minotti, L., and Berthoz, A. (2003). Reappraisal of the human vestibular cortex by cortical electrical stimulation study. Ann. Neurol. 54, 615-624. doi: 10.1002/ana.10726

Kalén, P., Karlson, M., and Wiklund, L. (1985). Possible excitatory amino acid afferents to nucleus raphe dorsalis of the rat investigated with retrograde wheat germ agglutinin and d-[3H] aspartate tracing. Brain Res. 360, 285-297. doi: 10. 1016/0006-8993(85)91244-2

Karim, H. T., Fuhrman, S. I., Furman, J. M., and Huppert, T. J. (2013). Neuroimaging to detect cortical projection of vestibular response to caloric stimulation in young and older adults using functional near-infrared spectroscopy (fNIRS). Neuroimage 76, 1-10. doi: 10.1016/j.neuroimage.2013.02.061

Keizer, A., Smeets, M. A. M., Dijkerman, H. C., Uzunbajakau, S. A., Van Elburg, A., and Postma, A. (2013). Too fat to fit through the door: first evidence for disturbed body-scaled action in anorexia nervosa during locomotion. PLos One 8:e64602. doi: 10.1371/journal.pone.0064602

Kerkhoff, G., Hildebrandt, H., Reinhart, S., Kardinal, M., Dimova, V., and Utz, K. S. (2011). A long-lasting improvement of tactile extinction after galvanic vestibular stimulation: two Sham-stimulation controlled case studies. Neuropsychologia 49, 186-195. doi: 10.1016/j.neuropsychologia.2010.11.014

Korner, A. F., and Thoman, E. B. (1972). The relative efficacy of contact and vestibular-proprioceptive stimulation in soothing neonates. Child Dev. 43, 443 453. doi: $10.2307 / 1127547$

Kosslyn, S. M., Ganis, G., and Thompson, W. L. (2001). Neural foundations of imagery. Nat. Rev. Neurosci. 9, 635-642. doi: 10.1038/35090055

la Fougère, C., Zwergal, A., Rominger, A., Förster, S., Fesl, G., Dieterich, M., et al. (2010). Real versus imagined locomotion: a [18F]-FDG PET-fMRI comparison. Neuroimage 50, 1589-1598. doi: 10.1016/j.neuroimage.2009.12.060

Lakoff, G., and Johnson, M. (1980). Conceptual metaphor in everyday language. J. Philos. 77, 453-486. doi: 10.2307/2025464

le Chapelain, L., Beis, J. M., Paysant, J., and André, J. M. (2001). Vestibular caloric stimulation evokes phantom limb illusions in patients with paraplegia. Spinal Cord 39, 85-87. doi: 10.1038/sj.sc.3101093 
Lenggenhager, B., Hilti, L., Palla, A., Macauda, G., and Brugger, P. (2014). Vestibular stimulation does not diminish the desire for amputation. Cortex 54, 210-212. doi: 10.1016/j.cortex.2014.02.004

Lenggenhager, B., Lopez, C., and Blanke, O. (2008). Influence of galvanic vestibular stimulation on egocentric and object-based mental transformations. Exp. Brain Res. 184, 211-221. doi: 10.1007/s00221-007-1095-9

Leone, G., Lipshits, M., Gurfinkel, V., and Berthoz, A. (1995). Is there an effect of weightlessness on mental rotation of three-dimensional objects? Cogn. Brain Res. 2, 255-267. doi: 10.1016/0926-6410(95)90017-9

Levine, J., Toder, D., Geller, V., Kraus, M., Gauchman, T., Puterman, M., et al. (2012). Beneficial effects of caloric vestibular stimulation on denial of illness and manic delusions in schizoaffective disorder: a case report. Brain Stimul. 5, 267-273. doi: 10.1016/j.brs.2011.03.004

Lobel, E., Kleine, J. F., Le Bihan, D., Leroy-Willig, A., and Berthoz, A. (1998). Functional MRI of galvanic vestibular stimulation. J. Neurophysiol. 80, 26992709.

Loetscher, T., Schwarz, U., Schubiger, M., and Brugger, P. (2008). Head turns bias the brain's internal random generator. Curr. Biol. 18, R60-R62. doi: 10.1016/j. cub.2007.11.015

Longo, M. R., Betti, V., Aglioti, S. M., and Haggard, P. (2009). Visually induced analgesia: seeing the body reduces pain. J. Neurosci. 29, 12125-12130. doi: 10. 1523/jneurosci.3072-09.2009

Lopez, C., and Blanke, O. (2011). The thalamocortical vestibular system in animals and humans. Brain Res. Rev. 67, 119-146. doi: 10.1016/j.brainresrev.2010.12.002

Lopez, C., Bieri, C. P., Preuss, N., and Mast, F. W. (2012a). Tactile and vestibular mechanisms underlying ownership for body parts: a non-visual variant of the rubber hand illusion. Neurosci. Lett. 511, 120-124. doi: 10.1016/j.neulet.2012. 01.055

Lopez, C., Blanke, O., and Mast, F. W. (2012b). The human vestibular cortex revealed by coordinate-based activation likelihood estimation meta-analysis. Neuroscience 212, 159-179. doi: 10.1016/j.neuroscience.2012.03.028

Lopez, C., Falconer, C., and Mast, F. W. (2013). Being moved by the self and others: influence of empathy on self-motion perception. PLos One 8:e48293. doi: 10. 1371/journal.pone.0048293

Lopez, C., Lenggenhager, B., and Blanke, O. (2010). How vestibular stimulation interacts with illusory hand ownership. Conscious. Cogn. 19, 33-47. doi: 10. 1016/j.concog.2009.12.003

Lopez, C., Schreyer, H.-M., Preuss, N., and Mast, F. W. (2012c). Vestibular stimulation modifies the body schema. Neuropsychologia 50, 1830-1837. doi: 10.1016/j. neuropsychologia.2012.04.008

Lopez, C., Vibert, D., and Mast, F. W. (2011). Can imagined whole-body rotations improve vestibular compensation? Med. Hypotheses 76, 816-819. doi: 10.1016/j. mehy.2011.02.026

Manzoni, D., Pompeiano, O., Barnes, C., Stampacchia, G., and D'Ascanio, P. (1989). Convergence and interaction of neck and macular vestibular inputs on locus coeruleus and subcoeruleus neurons. Pflug. Arch. 413, 580-598. doi: 10. 1007/bf00581807

Mast, F. W., Berthoz, A., and Kosslyn, S. M. (2001). Mental imagery of visual motion modifies the perception of roll-vection stimulation. Perception 30, 945957. doi: 10.1068/p3088

Mast, F. W., Ganis, G., Christie, S., and Kosslyn, S. M. (2003). Four types of visual mental imagery processing in upright and tilted observers. Brain Res. Cogn. Brain Res. 17, 238-247. doi: 10.1016/s0926-6410(03)00111-3

Mast, F. W., Kosslyn, S. M., and Berthoz, A. (1999). Visual mental imagery interferes with allocentric orientation judgements. Neuroreport 10, 3549-3553. doi: 10. 1097/00001756-199911260-00016

Mast, F. W., Merfeld, D. M., and Kosslyn, S. M. (2006). Visual mental imagery during caloric vestibular stimulation. Neuropsychologia 44, 101-109. doi: 10 . 1016/j.neuropsychologia.2005.04.005

Matsakis, Y., Lipshits, M., Gurfinkel, V., and Berthoz, A. (1993). Effects of prolonged weightlessness on mental rotation of three-dimensional objects. Exp. Brain Res. 94, 152-162. doi: 10.1007/bf00230478

McGeoch, P. D., and Ramachandran, V. S. (2008). Vestibular stimulation can relieve central pain of spinal origin. Spinal Cord 46, 756-757. doi: 10.1038/sc. 2008.47

McGeoch, P. D., Williams, L. E., Lee, R. R., and Ramachandran, V. S. (2008). Behavioural evidence for vestibular stimulation as a treatment for central poststroke pain. J. Neurol. Neurosurg. Psychiatry 79, 1298-1301. doi: 10.1136/jnnp. 2008.146738
McGeoch, P. D., Williams, L. E., Song, T., Lee, R. R., Huang, M., and Ramachandran, V. S. (2009). Post-stroke tactile allodynia and its modulation by vestibular stimulation: a MEG case study. Acta Neurol. Scand. 119, 404-409. doi: 10.1111/j.1600-0404.2008.01106.x

McKay, R., Tamagni, C., Palla, A., Krummenacher, P., Hegemann, S. C., Straumann, D., et al. (2013). Vestibular stimulation attenuates unrealistic optimism. Cortex 49, 2272-2275. doi: 10.1016/j.cortex.2013.04.005

Merfeld, D. M. (2012). "Spatial orientation and the vestibular system," in Sensation and Perception, eds J. M. Wolfe, K. R. Kluender, D. M. Levi 3rd Edn. (Sunderland, MA: Sinauer Associates Inc.), 328-361.

Mertz, S., and Lepecq, J.-C. (2001). Imagined body orientation and perception of the visual vertical. Psychol. Res. 65, 64-70. doi: 10.1007/s004260000048

Mertz, S., Belkhenchir, S., and Lepecq, J.-C. (2000). Evidence of imagined passive self-motion through imagery-perception interaction. Acta Psychol. (Amst) 105, 57-78. doi: 10.1016/s0001-6918(00)00048-2

Miles, L. K., Nind, L. K., and Macrae, C. N. (2010). Moving through time. Psychol. Sci. 21, 222-223. doi: 10.1177/0956797609359333

Miller, S. M., and Ngo, T. T. (2007). Studies of caloric vestibular stimulation: implications for the cognitive neurosciences, the clinical neurosciences and neurophilosophy. Acta Neuropsychiatr. 19, 183-203. doi: 10.1111/j.1601-5215. 2007.00208.x

Miller, S. M., Gynther, B. D., Heslop, K. R., Liu, G. B., Mitchell, P. B., Ngo, T. T., et al. (2003). Slow binocular rivalry in bipolar disorder. Psychol. Med. 33, 683692. doi: 10.1017/S0033291703007475

Miller, S. M., Liu, G. B., Ngo, T. T., Hooper, G., Riek, S., Carson, R. G., et al. (2000). Interhemispheric switching mediates perceptual rivalry. Curr. Biol. 10, 383-392. doi: 10.1016/s0960-9822(00)00416-4

Moseley, G. L. (2005). Distorted body image in complex regional pain syndrome. Neurology 65, 773. doi: 10.1097/00132985-200510000-00015

Moseley, G. L. (2008). I can't find it! Distorted body image and tactile dysfunction in patients with chronic back pain. Pain 140, 239-243. doi: 10.1016/j.pain.2008. 08.001

Moseley, G. L., Gallace, A., and Spence, C. (2012). Bodily illusions in health and disease: physiological and clinical perspectives and the concept of a cortical 'body matrix'. Neurosci. Biobehav. Rev. 36, 34-46. doi: 10.1016/j.neubiorev.2011. 03.013

Moseley, G. L., Parsons, T. J., and Spence, C. (2008a). Visual distortion of a limb modulates the pain and swelling evoked by movement. Curr. Biol. 18, R1047R1048. doi: 10.1016/j.cub.2008.09.031

Moseley, G. L., and Wiech, K. (2009). The effect of tactile discrimination training is enhanced when patients watch the reflected image of their unaffected limb during training. Pain 144, 314-319. doi: 10.1016/j.pain.2009.04.030

Moseley, G. L., Zalucki, N. M., and Wiech, K. (2008b). Tactile discrimination, but not tactile stimulation alone, reduces chronic limb pain. Pain 137, 600-608. doi: 10.1016/j.pain.2007.10.021

Nishiike, S., Guldin, W. O., and Bäurle, J. (2000). Corticofugal connections between the cerebral cortex and the vestibular nuclei in the rat. J. Comp. Neurol. 420, 363-372. doi: 10.1002/(sici) 1096-9861(20000508)420:3<363::aid-cne7> 3.0.co; $2-\mathrm{x}$

Péruch, P., Borel, L., Magnan, J., and Lacour, M. (2005). Direction and distance deficits in path integration after unilateral vestibular loss depend on task complexity. Brain Res. Cogn. Brain Res. 25, 862-872. doi: 10.1016/j.cogbrainres. 2005.09.012

Péruch, P., Lopez, C., Redon-Zouiteni, C., Escoffier, G., Zeitoun, A., Sanjuan, M., et al. (2011). Vestibular information is necessary for maintaining metric properties of representational space: evidence from mental imagery. Neuropsychologia 49, 3136-3144. doi: 10.1016/j.neuropsychologia.2011.07.026

Pettigrew, J. D., and Miller, S. M. (1998). A 'sticky' interhemispheric switch in bipolar disorder? Proc. R. Soc. Lond. B. Biol. 265, 2141-2148. doi: 10.1098/rspb. 1998.0551

Preuss, N., Hasler, G., and Mast, F. W. (2014a). Caloric vestibular stimulation modulates affective control and mood. Brain Stimul. 7, 133-140. doi: 10.1016/j. brs.2013.09.003

Preuss, N., Mast, F. W., and Hasler, G. (2014b). Purchase decision-making is modulated by vestibular stimulation. Front. Behav. Neurosci. 8:51. doi: 10 . 3389/fnbeh.2014.00051

Ramachandran, V. S., Brang, D., and McGeoch, P. D. (2009). Size reduction using Mirror Visual Feedback (MVF) reduces phantom pain. Neurocase 15, 357-360. doi: 10.1080/13554790903081767 
Ramachandran, V. S., McGeoch, P. D., and Williams, L. (2007a). Can vestibular caloric stimulation be used to treat Dejerine-Roussy Syndrome? Med. Hypotheses 69, 486-488. doi: 10.1016/j.mehy.2006.12.036

Ramachandran, V. S., McGeoch, P. D., Williams, L., and Arcilla, G. (2007b). Rapid relief of thalamic pain syndrome induced by vestibular caloric stimulation. Neurocase 13, 185-188. doi: 10.1080/13554790701450446

Redfern, M. S., Furman, J. M., and Jacob, R. G. (2007). Visually induced postural sway in anxiety disorders. J. Anxiety Disord. 21, 704-716. doi: 10.1016/j.janxdis. 2006.09.002

Ried, A. M. S., and Aviles, M. (2007). Asymmetries of vestibular dysfunction in major depression. Neuroscience 144, 128-134. doi: 10.1016/j.neuroscience.2006. 09.023

Roberts, R., Callow, N., Hardy, L., Markland, D., and Bringer, J. (2008). Movement imagery ability: development and assessment of a revised version of the vividness of movement imagery questionnaire. J. Sport Exerc. Psychol. 30, B200-B221.

Rode, G., Charles, N., Perenin, M. T., Vighetto, A., Trillet, M., and Aimard, G. (1992). Partial remission of hemiplegia and somatoparaphrenia through vestibular stimulation in a case of unilateral neglect. Cortex 28, 203-208. doi: 10 . 1016/s0010-9452(13)80048-2

Rode, G., Vallar, G., Revol, P., Tilikete, C., Jacquin-Courtois, S., Rossetti, Y., et al. (2012). Facial macrosomatognosia and pain in a case of Wallenberg's syndrome: selective effects of vestibular and transcutaneous stimulations. Neuropsychologia 50, 245-253. doi: 10.1016/j.neuropsychologia.2011.11.018

Rodionov, V., Zislin, J., and Elidan, J. (2004). Imagination of body rotation can induce eye movements. Acta Otolaryngol. 124, 684-689. doi: 10. 1080/00016480410017017

Rule, R. R., Shimamura, A. P., and Knight, R. T. (2002). Orbitofrontal cortex and dynamic filtering of emotional stimuli. Cogn. Affect. Behav. Neurosci. 2, 264-270. doi: $10.3758 /$ cabn.2.3.264

Russell, N. A., Horii, A., Smith, P. F., Darlington, C. L., and Bilkey, D. K. (2006). Lesions of the vestibular system disrupt hippocampal theta rhythm in the rat. J. Neurophysiol. 96, 4-14. doi: 10.1152/jn.00953.2005

Saman, Y., Bamiou, D. E., Gleeson, M., and Dutia, M. B. (2012). Interactions between stress and vestibular compensation-a review. Front. Neurol. 3:116. doi: 10.3389/fneur.2012.00116

Samoudi, G., Nissbrandt, H., Dutia, M. B., and Bergquist, F. (2012). Noisy galvanic vestibular stimulation promotes GABA release in the substantia nigra and improves locomotion in hemiparkinsonian rats. Plos One 7:e29308. doi: 10. 1371/journal.pone.0029308

Sauvan, X. M. (1999). Orientation constancy in neurons of monkey visual cortex. Vis. Cogn. 6, 43-54. doi: 10.1080/713756803

Sauvan, X. M., and Peterhans, E. (1995). "Neural integration of visual information and direction of gravity in prestriate cortex of the alert monkey," in Multisensory Control of Posture, eds T. Mergner and F. Hlavacka (New York: Springer), 43-49.

Schautzer, F., Hamilton, D. A., Kalla, R., Strupp, M., and Brandt, T. (2003). Spatial memory deficits in patients with chronic bilateral vestibular failure. Ann. N. Y. Acad. Sci. 1004, 316-324. doi: 10.1196/annals.1303.029

Schilder, P. (1935). The Image and Appearance of the Human Body. London: Kegan Paul.

Schlack, A., Hoffmann, K. P., and Bremmer, F. (2002). Interaction of linear vestibular and visual stimulation in the macaque ventral intraparietal area (VIP). Eur. J. Neurosci. 16, 1877-1886. doi: 10.1046/j.1460-9568.2002.02251.x

Schlindwein, P., Mueller, M., Bauermann, T., Brandt, T., Stoeter, P., and Dieterich, M. (2008). Cortical representation of saccular vestibular stimulation: VEMPs in fMRI. Neuroimage 39, 19-31. doi: 10.1016/j.neuroimage.2007.08.016

Schmidt, L., Utz, K. S., Depper, L., Adams, M., Schaadt, A. K., Reinhart, S., et al. (2013). Now you feel both: galvanic vestibular stimulation induces lasting improvements in the rehabilitation of chronic tactile extinction. Front. Hum. Neurosci. 7:90. doi: 10.3389/fnhum.2013.00090

Schuerger, R. J., and Balaban, C. D. (1999). Organization of the coeruleo-vestibular pathway in rats, rabbits and monkeys. Brain Res. Rev. 30, 189-217. doi: 10. 1016/s0165-0173(99)00015-6

Seno, T., Ito, H., and Sunaga, S. (2011). Attentional load inhibits vection. Atten. Percept. Psychophys. 73, 1467-1476. doi: 10.3758/s13414-011-0129-3

Shepard, R. N., and Metzler, J. (1971). Mental rotation of three-dimensional objects. Science 171, 701-703.

Sklare, D. A., Stein, M. B., Pikus, A. M., and Uhde, T. W. (1990). Dysequilibrium and audiovestibular function in panic disorder: symptom profiles and test findings. Am. J. Otol. 11, 338-341.
Smith, P. F., Darlington, C., and Zheng, Y. (2010). Move it or lose it-is stimulation of the vestibular system necessary for normal spatial memory? Hippocampus 20, 36-43.

Smith, P. F., and Zheng, Y. (2013). From ear to uncertainty: vestibular contributions to cognitive function. Front. Integr. Neurosci. 7:84. doi: 10.3389/fnint.2013. 00084

Stackman, R. W., Clark, A. S., and Taube, J. S. (2002). Hippocampal spatial representations require vestibular input. Hippocampus 12, 291-303. doi: 10. 1002/hipo.1112

Tarnutzer, A. A., Bockisch, C. J., and Straumann, D. (2010). Roll-dependent modulation of the subjective visual vertical: contributions of head-and trunkbased signals. J. Neurophysiol. 103, 934-941. doi: 10.1152/jn.00407.2009

Tucker, D. M. (1981). Lateral brain function, emotion and conceptualization. Psychol. Bull. 89, 19-46. doi: 10.1037/0033-2909.89.1.19

Ulrich, R., Eikmeier, V., de la Vega, I., Fernández, S. R., Alex-Ruf, S., and Maienborn, C. (2012). With the past behind and the future ahead: back-to-front representation of past and future sentences. Mem. Cognit. 40, 483-495. doi: 10. 3758/s13421-011-0162-4

Ulrich, R., and Maienborn, C. (2010). Left-right coding of past and future in language: the mental timeline during sentence processing. Cognition 117, 126138. doi: 10.1016/j.cognition.2010.08.001

Utz, K. S., Dimova, V., Oppenländer, K., and Kerkhoff, G. (2010). Electrified minds: transcranial direct current stimulation (tDCS) and galvanic vestibular stimulation (GVS) as methods of non-invasive brain stimulation in neuropsychologya review of current data and future implications. Neuropsychologia 48, 27892810. doi: 10.1016/j.neuropsychologia.2010.06.002

Vallar, G., Bottini, G., Rusconi, M. L., and Sterzi, R. (1993). Exploring somatosensory hemineglect by vestibular stimulation. Brain 116, 71-86. doi: 10 . 1093/brain/116.1.71

Vallar, G., Sterzi, R., Bottini, G., Cappa, S., and Rusconi, M. L. (1990). Temporary remission of left hemianesthesia after vestibular stimulation. A sensory neglect phenomenon. Cortex 26, 123-131. doi: 10.1016/s0010-9452(13)80078-0

van Elk, M., and Blanke, O. (2013). Imagined own-body transformations during passive self-motion. Psychol. Res. 78, 18-27. doi: 10.1007/s00426-013-0486-8

Viaud-Delmon, I., Berthoz, A., and Jouvent, R. (2002). Multisensory integration for spatial orientation in trait anxiety subjects: absence of visual dependence. Eur. Psychiatry 17, 194-199. doi: 10.1016/s0924-9338(02)00667-3

Vingerhoets, G., Santens, P., Van Laere, K., Lahorte, P., Dierckx, R. A., and De Reuck, J. (2001). Regional brain activity during different paradigms of mental rotation in healthy volunteers: a positron emission tomography study. Neuroimage 13, 381-391. doi: 10.1006/nimg.2000.0690

Wand, B. M., Szpak, L., George, P. J., Bulsara, M. K., O’Connell, N. E., and Moseley, G. L. (2014). Moving in an environment of induced sensorimotor incongruence does not influence pain sensitivity in healthy volunteers: a randomised withinsubject experiment. Plos One 9:e93701. doi: 10.1371/journal.pone.0093701

Wertheim, A. H., Mesland, B. S., and Bles, W. (2001). Cognitive suppression of tilt sensations during linear horizontal self-motion in the dark. Perception 30, 733 742. doi: 10.1068/p3092

Wilkinson, D., Nicholls, S., Pattenden, C., Kilduff, P., and Milberg, W. (2008). Galvanic vestibular stimulation speeds visual memory recall. Exp. Brain. Res. 189, 243-248. doi: 10.1007/s00221-008-1463-0

Wraga, M., Shephard, J. M., Church, J. A., Inati, S., and Kosslyn, S. M. (2005). Imagined rotations of self versus objects: an fMRI study. Neuropsychologia 43 , 1351-1361. doi: 10.1016/j.neuropsychologia.2004.11.028

Yamaguchi, S., and Knight, R. T. (1990). Gating of somatosensory input by human prefrontal cortex. Brain Res. 521, 281-288. doi: 10.1016/0006-8993(90) 91553-s

Yamaguchi, S., and Knight, R. T. (1991). Anterior and posterior association cortex contributions to the somatosensory P300. J. Neurosci. 11, 2039-2054.

Yardley, L., Gardner, M., Leadbetter, A., and Lavie, N. (1999). Effect of articulatory and mental tasks on postural control. Neuroreport 10, 215-219. doi: 10. 1097/00001756-199902050-00003

Yardley, L., Luxon, L., Lear, S., Britton, J., and Bird, J. (1994). Vestibular and posturographic test results in people with symptoms of panic and agoraphobia. J. Audiol. Med. 3, 48-65.

Yardley, L., Masson, E., Verschuur, C., Haacke, N., and Luxon, L. (1992). Symptoms, anxiety and handicap in dizzy patients: development of the vertigo symptom scale. J. Psychosom. Res. 36, 731-741. doi: 10.1016/0022-3999(92) 90131-k 
Zheng, Y., Horii, A., Appleton, I., Darlington, C., and Smith, P. (2001). Damage to the vestibular inner ear causes long-term changes in neuronal nitric oxide synthase expression in the rat hippocampus. Neuroscience 105, 1-5. doi: 10. 1016/s0306-4522(01)00217-2

Zheng, Y., Wilson, G., Stiles, L., and Smith, P. F. (2013). Glutamate receptor subunit and calmodulin kinase II expression, with and without $\mathrm{T}$ maze training, in the rat hippocampus following bilateral vestibular deafferentation. PLoS One 8:e54527. doi: 10.1371/journal.pone.0054527

Zheng, Y., Balabhadrapatruni, S., Baek, J. H., Chung, P., Gliddon, C., Zhang, M., et al. (2012). The effects of bilateral vestibular loss on hippocampal volume, neuronal number and cell proliferation in rats. Front. Neurol. 28:20. doi: 10. 3389/fneur.2012.00020

zu Eulenburg, P., Baumgartner, U., Treede, R. D., and Dieterich, M. (2013b). Interoceptive and multimodal functions of the operculo-insular cortex: tactile, nociceptive and vestibular representations. Neuroimage 83, 75-86. doi: 10 . 1016/j.neuroimage.2013.06.057

zu Eulenburg, P., Caspers, S., Roski, C., and Eickhoff, S. B. (2012). Meta-analytical definition and functional connectivity of the human vestibular cortex. Neuroimage 60, 162-169. doi: 10.1016/j.neuroimage.2011. 12.032 zu Eulenburg, P., Muller-Forell, W., and Dieterich, M. (2013a). On the recall of vestibular sensations. Brain Struct. Funct. 218, 255-267. doi: 10.1007/s00429012-0399-0

Conflict of Interest Statement: The authors declare that the research was conducted in the absence of any commercial or financial relationships that could be construed as a potential conflict of interest.

Received: 08 January 2014; accepted: 13 May 2014; published online: 27 May 2014. Citation: Mast FW, Preuss N, Hartmann M and Grabherr L (2014) Spatial cognition, body representation and affective processes: the role of vestibular information beyond ocular reflexes and control of posture. Front. Integr. Neurosci. 8:44. doi: 10.3389/ fnint.2014.00044

This article was submitted to the journal Frontiers in Integrative Neuroscience.

Copyright (c) 2014 Mast, Preuss, Hartmann and Grabherr. This is an open-access article distributed under the terms of the Creative Commons Attribution License (CC $B Y$ ). The use, distribution or reproduction in other forums is permitted, provided the original author(s) or licensor are credited and that the original publication in this journal is cited, in accordance with accepted academic practice. No use, distribution or reproduction is permitted which does not comply with these terms. 